\title{
Disabling Standby Converter with Phase-Shifted Full-Bridge Converter in Server Power Supplies
}

\author{
Jong-Woo Kim ${ }^{1}$, Duk-You Kim ${ }^{1}$, Chong-Eun Kim², Jae-Hyun Kim ${ }^{1}$ and Gun-Woo Moon ${ }^{1}$ \\ ${ }^{1}$ Department of Electrical Engineering, KAIST, Republic of Korea \\ ${ }^{2}$ Samsung Electro-Mechanics, Republic of Korea \\ gwmoon@ee.kaist.ac.kr
}

\begin{abstract}
This paper proposes to disable standby converter for improving the efficiency of a server computer power supply. By disabling the standby flyback converter after DC/DC stage is turned on, losses in standby flyback converter are removed in normal mode. When it is disabled, all outputs of the standby flyback converter are provided by phase-shifted full-bridge (PSFB) converter, so that the PSFB converter operates by itself. Since PSFB converter has much higher efficiency than the standby flyback converter, the system efficiency can be improved in the entire load condition. The feasibility of the proposed structure has been verified with $90-265 \mathrm{~V}_{\text {rms }}, 400 \mathrm{~V}$ link voltage, $12 \mathrm{~V} / 62.5 \mathrm{~A}$ main output, and $12 \mathrm{~V} / 2.1 \mathrm{~A}$ standby output server power system.
\end{abstract}

Keywords- server power supply, phase-shifted full-bridge (PSFB) converter, standby converter

\section{INTRODUCTION}

Nowadays, in order to reduce power consumption in the internet data centers, it is prompted to increase the efficiency of server computer power supplies. Generalized certifications, such as Climate Savers Computing Initiative (CSCI) and 80 PLUS, are strongly recommending to achieve higher efficiency [1]-[2]. It can be noted that the efficiency in light load condition is getting more important in the server power supplies, because the brand-new certification requires meeting $10 \%$ load efficiency, whereas the former certification does not [1].

As shown in Fig. 1, a server power system consists of boost PFC, DC/DC conversion, and the standby converter stage. Boost PFC stage provides the input voltage of $\mathrm{DC} / \mathrm{DC}$ conversion stage, $V_{\text {link }}$, satisfying the requirements of power factor and total harmonics distortion. DC/DC conversion stage provides tightly regulated output voltage, $V_{\text {out main. }}$. In this stage, phase-shifted full-bridge (PSFB) converter is widely used, since it shows powerful advantages for large output current specification: simple control, small RMS current in secondary side, and inherent zero-voltage-switching (ZVS) operation [3]-[8]. The standby converter provides standby output, $V_{\text {out } S T B}$, and supply voltage for controllers in the system. In the standby converter stage, flyback converter is one of the most attractive topologies, because it has small size, wide input-range capability, and low cost [9]-[10].

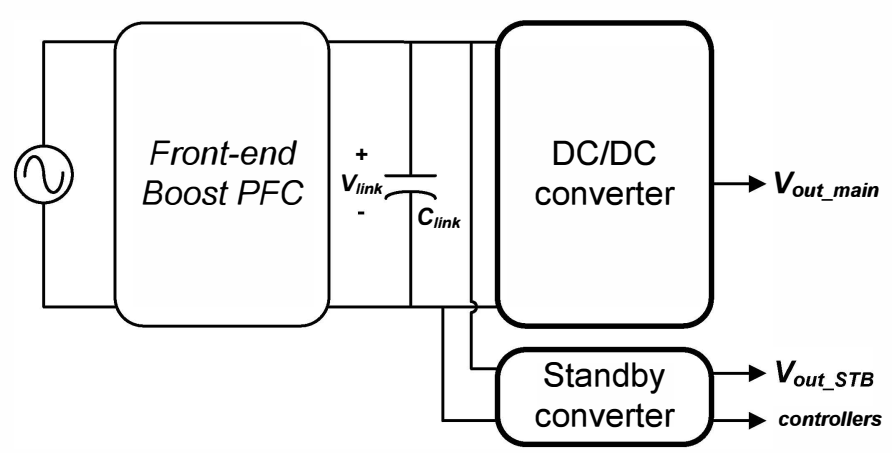

Fig.1 Overall structure of a server power system.

However, since the standby flyback converter suffers from high voltage stress on switch, hard-switching loss, and snubber loss [9]-[10], it degrades the total system efficiency, especially in light load condition. Therefore, in order to improve overall efficiency, it is required to reduce the losses in the standby flyback converter. There have been many approaches to improve the efficiency of flyback converter [9]-[10]. However, these approaches require additional components causing high cost and low power density.

For these reasons, standby-flyback-integrating structures have been studied in recent years [11]-[13]. By integrating the standby flyback converter in the main power conversion stage, these works reduced switching losses, resulting in improved efficiency of the system. However, these works require additional components and complex control signals. Also, since these works make the transformer core of the flyback converter operate at all times, continuous core loss of the standby flyback converter is caused.

This letter proposes to disable the stnadby flyback converter in normal mode. In the standby mode, the standby outputs are provided by the standby flyback converter. However, after DC/DC conversion stage is turned on, all losses in the standby flyback converter are removed in the proposed structure, by disabling the standby flyback converter. The standby output is provided by the main output, and the supply voltage for primary side controllers are provided by an auxiliary turn of the main transformer of PSFB converter. Since PSFB converter has much higher efficiency than the flyback converter, the total system efficiency is improved. 


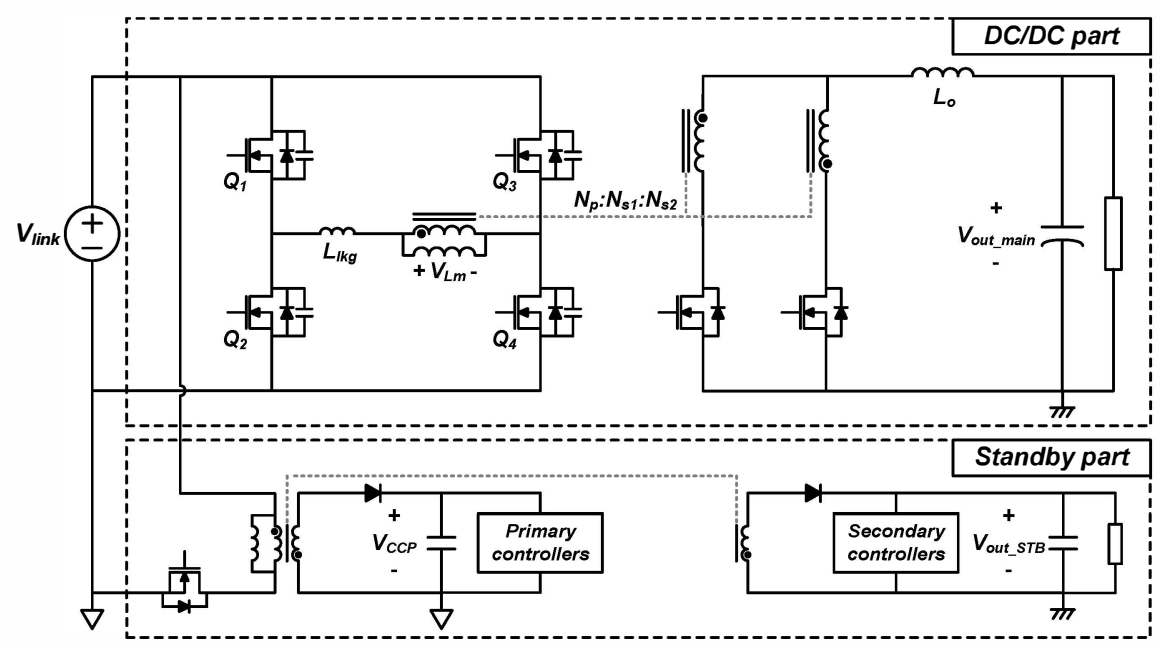

(a)

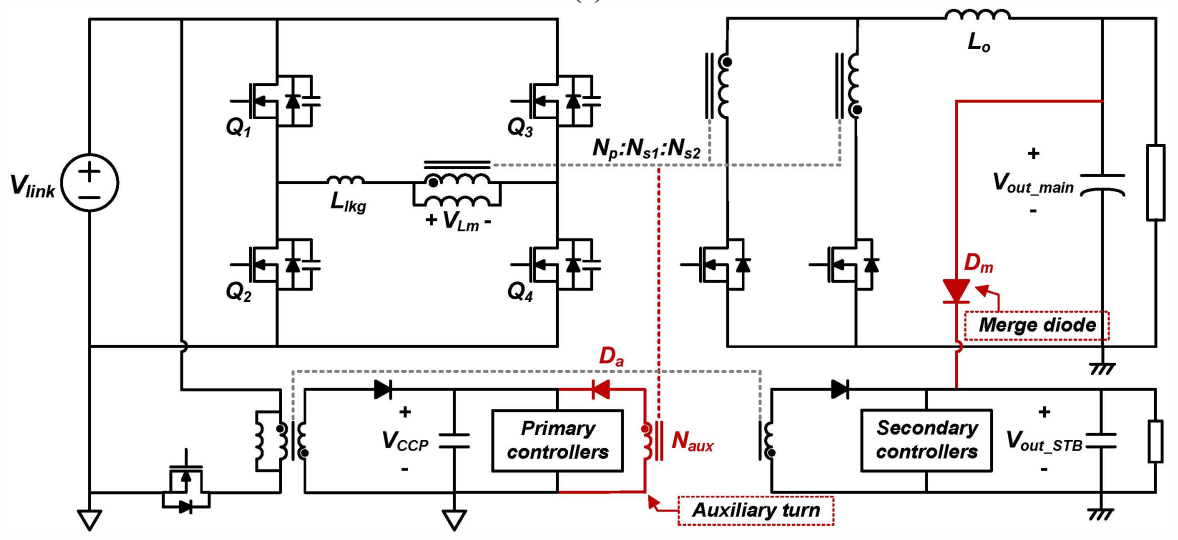

(b)

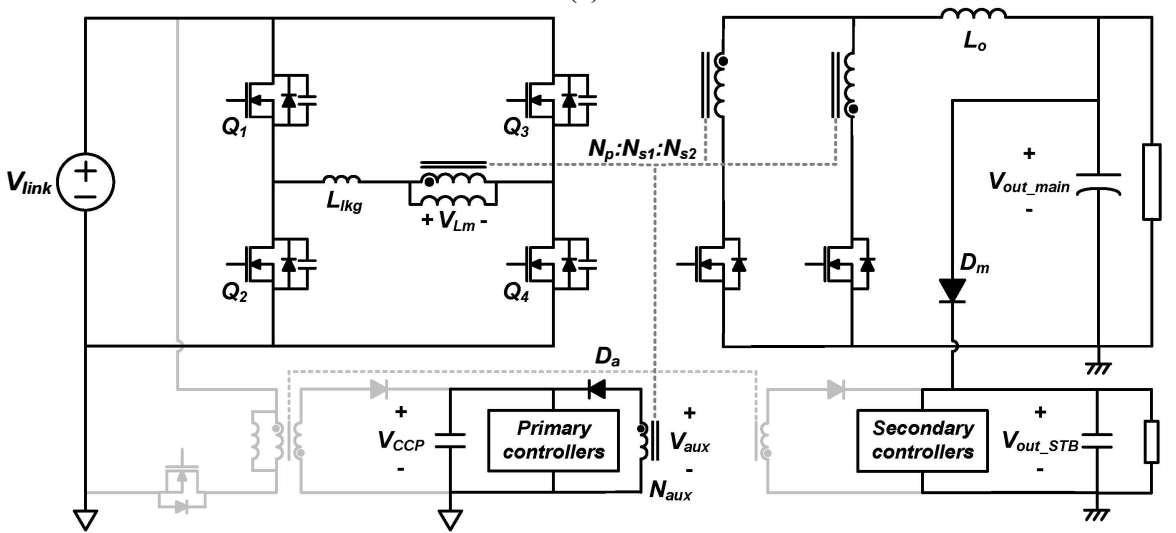

(c)

Fig. 2 Schematics for (a) the conventional structure (b) the proposed structure (c) the proposed structure in normal mode.

\section{The Proposed Structure AND CHARACTERISTICS}

Fig. 2(a) shows a conventional DC/DC converter and standby converter structure of a server power system. In order to avoid complexity, the front-end boost PFC is omitted. In the conventional structure, PSFB converter provides $V_{\text {out main }}$. The standby flyback converter provides $V_{\text {out }}$ STB, and it provides $V_{c c p}$ with the auxiliary winding of the standby transformer, to drive controllers in primary side of the server power system.

The proposed structure to remove losses in the standby flyback converter is shown in Fig. 2(b). In the proposed structure, PSFB converter provides all outputs of the standby flyback converter when it is turned off in normal mode. $V_{\text {out main }}$ provides the standby output, via merge diode $D_{m}$. Since the standby output voltage is same with the main output voltage, by using small voltage-drop diode, standby output can be provided by PSFB converter. With the additional winding of the main transformer, $N_{\text {aux }}$, in PSFB converter, $V_{c c p}$ can be provided every switching period.

As shown in Fig. 2(c), with the proposed structure, the 


\begin{tabular}{|c|c|c|c|}
\hline Q2 & Q1 & Q2 & Q1 \\
\hline \multirow[t]{4}{*}{ Q3 } & Q4 & Q3 & \\
\hline & $V_{\text {aux }}-4$ & $V_{\text {link }} N_{\text {aux }} / N_{p}$ & \\
\hline & $-V_{\text {link }} N_{\text {aux }} / N_{\text {, }}$ & & \\
\hline & $v_{c c p}-1$ & $\left|\overrightarrow{V_{a u x}}\right| \overrightarrow{\vec{\prime}} \mid$ & \\
\hline
\end{tabular}

(a)

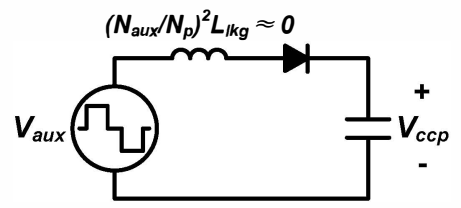

(b)

Fig.3 (a) Key waveforms (b) simplified equivalent circuit for $V_{c c p}$

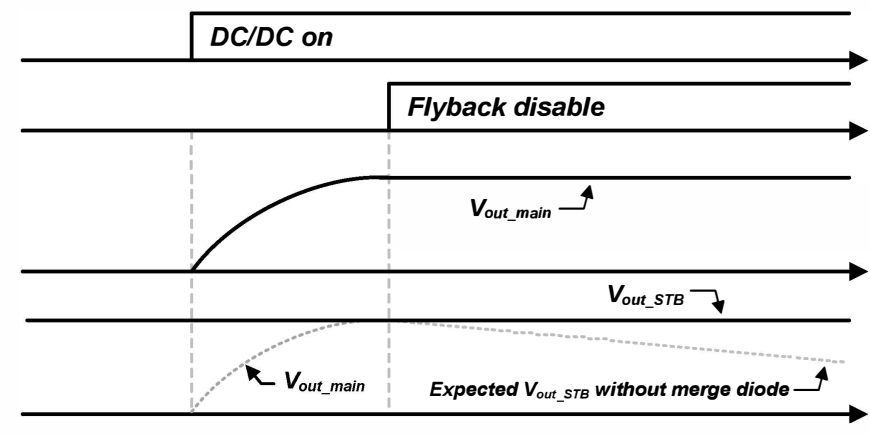

Fig. 4 Sequence for the proposed structure.

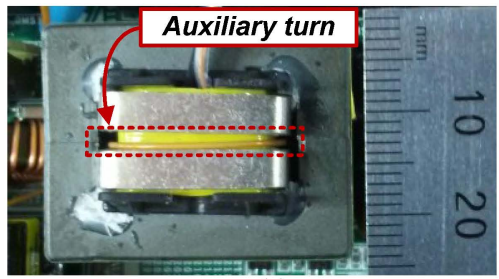

(a)

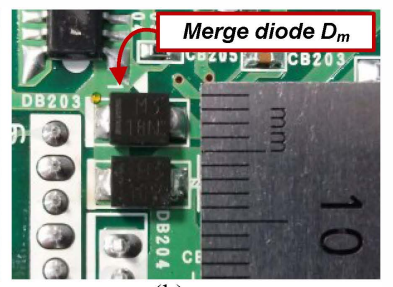

(b)
Fig.5 Implementation of the proposed structure (a) the auxiliary turn in main transformer (b) merge diode, $D_{m}$.

standby flyback converter can be completely turned off in normal mode, because all outputs of it can be provided by PSFB converter in the proposed structure.

\section{A. The auxiliary turns for primary side controllers, $N_{a u x}$}

Fig. 3(a) shows the key waveforms for $V_{c c p}$, when the standby flyback converter is disabled. PSFB converter controlled by phase-shifted signals of complementary gates, and voltage across magnetizing inductance of the main transformer, $V_{L m}$, alternates between $V_{\text {link }}$ and $-V_{\text {link }}$. Since the rectifier in the primary side, $D_{a}$, rectifies only a positive-half cycle of $V_{\text {aux }}$, the waveform of $V_{c c p}$ can be shown as Fig. 3(a). The simplified equivalent circuit for $V_{c c p}$ is shown in Fig. 3(b). Since $N_{p}$ is much larger than $N_{a u x}$ because of step-down ratio, the reflected leakage inductance is small enough to be

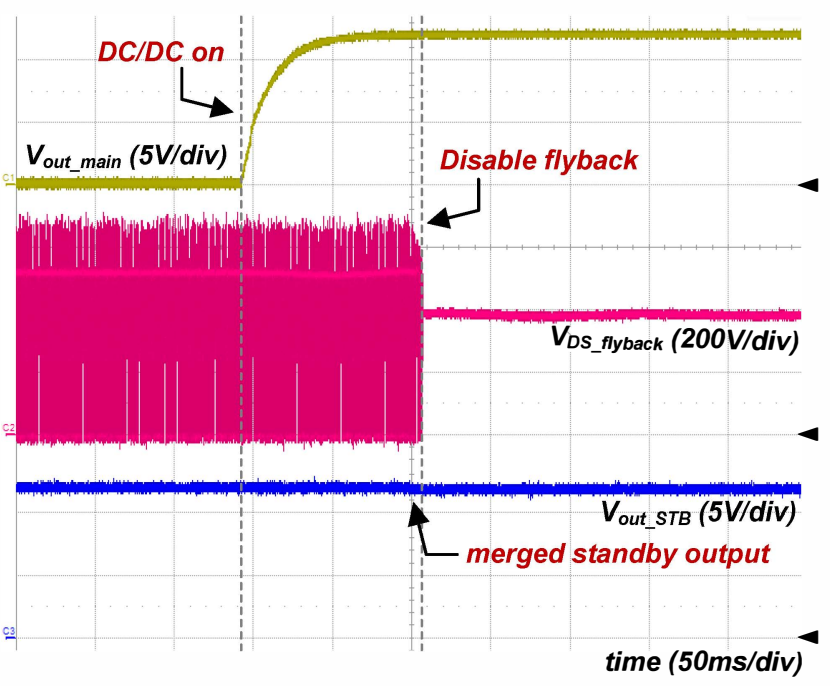

(a)

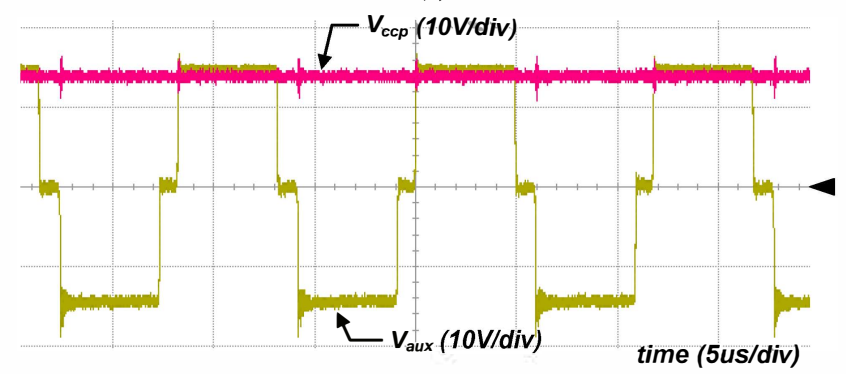

(b)

Fig. 6 Experimental waveforms of the proposed structure (a) disabling the standby flyback converter (b) $V_{a u x}$ and $V_{c c p}$.

neglected. Assuming that the capacitance for $V_{c c p}$ is large enough to neglect the voltage ripple of it, $V_{c c p}$ can be obtained by following equation:

$$
V_{c c p} \approx \frac{N_{a u x}}{N_{p}} V_{\text {in }}
$$

$N_{a u x}$ should be chosen to make $V_{c c p}$ larger than required voltage for primary side controllers. A linear regulator can be used to provide a precise voltage for the controllers, following $V_{c c p}$. In order to minimize the losses in the linear regulator, $N_{a u x}$ should be minimum, satisfying the condition that $V_{c c p}$ should be larger than the required voltage for the controllers..

\section{B. Sequence for the proposed structure}

Fig. 4 shows the sequence for the proposed structure. After $\mathrm{DC} / \mathrm{DC}$ converter is turned on, $V_{\text {out main }}$ increases and goes to its appropriate voltage. The standby flyback converter should be turned off after $V_{\text {out main }}$ is regulated because the value of $V_{\text {out STB }}$ is selected as a larger one between $V_{\text {out main }}$ and the expected $V_{\text {out }}$ STB without merge diode.

\section{EXPERIMENTAL RESULTS}

The feasibility of the proposed structure has been verified by a server power supply with $90-265 V_{\text {rms }}$ input, $400 V_{\text {link }}$, $12 \mathrm{~V} / 62.5 \mathrm{~A}$ main output, and $12 \mathrm{~V} / 2.1 \mathrm{~A}$ standby output. The 


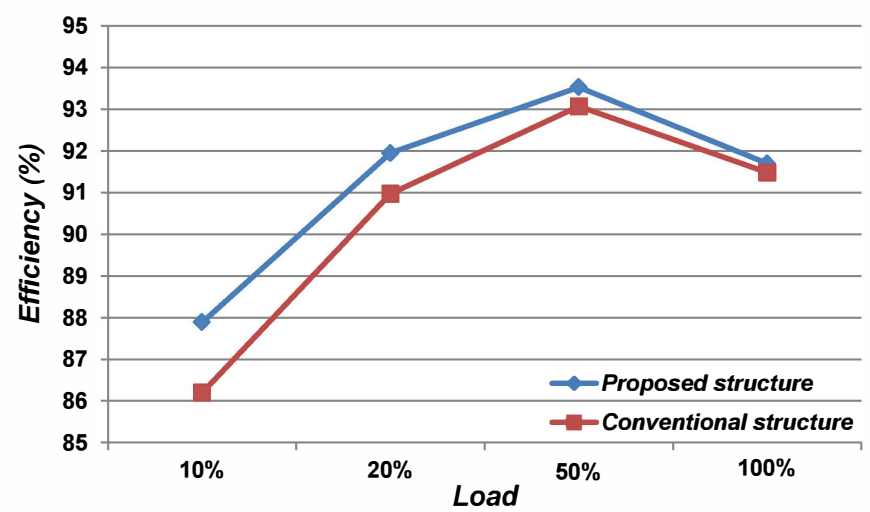

Fig.7 The total system efficiency.

system is designed with $N_{p}=26, N_{s l}=N_{s 2}=1, N_{a u x}=1$, and $L_{l k g}=15 \mu \mathrm{H}$. ES1D(200V, 1A, DO-214AC) is selected for $D_{a}$, M2FM3 $(30 \mathrm{~V}, 6 \mathrm{~A}, \mathrm{M} 2 \mathrm{~F})$ is selected for merge diode $D_{m}$, and ICE3AR0680JZ (switch-integrated controller) is selected for the standby flyback converter. Fig. 5 shows the implementation of the proposed structure. It can be noted that the auxiliary turn occupies very small window area, so that it does not affect the utilization factor of the main transformer. Also, the added merge diode $D_{m}$ is very small so that the power density of the total system is not degraded.

Fig. 6 shows the experimental waveforms of the proposed structure. As shown in Fig. 6(a), the standby flyback converter is disabled after $V_{\text {out main }}$ is regulated so that the losses of the standby flyback converter is removed. $V_{c c p}$ is provided by auxiliary turn from the main transformer, as shown in Fig. 6(b), so that the proposed structure operates by itself without the standby flyback converter. The additional winding provides $14 \mathrm{~V}$ of $V_{c c p}$ so that the primary controllers can operate with $12 \mathrm{~V}$ input voltage.

Fig. 7 shows the total system efficiency with the proposed structure. Since PSFB converter provides all outputs of the standby flyback converter with much higher efficiency, the system efficiency increases in the entire load condition. It should be noted that the efficiency is dramatically improved especially in light load condition, in accordance with the new efficiency requirement from 80 PLUS.

\section{CONCLUSION}

This paper proposes to disable the standby flyback converter in normal mode. Losses of the standby flyback converter are removed by disabling it in normal mode. The system efficiency is greatly increased, especially in light load conditions, since all outputs of the flyback converter is provided by PSFB, which has much higher efficiency. Since the proposed structure has very small number of additional components, it does not degrade the power density of the total system. Moreover, the proposed structure operates with a very simple control method: just disabling the standby flyback converter. Therefore, the proposed structure is simple and very powerful for improving the efficiency of a server power supply.

\section{ACKNOWLEDGMENT}

This work was supported by the National Research Foundation of Korea (NRF) grant funded by the Korea government (MEST) (No.2012-0000981).

\section{REFERENCES}

[1] 80Plus Program. [Online]. Available: http://www.plugloadsolutions.com

[2] Climate Savers Computing Initiative (CSCI). [Online]. Available: http://www.climatesaverscomputing.org

[3] I.-H. Cho, K.-M. Cho, J.-W. Kim, and G.-W. Moon, "A New PhaseShifted Full-Bridge Converter With Maximum Duty Operation for Server Power System," IEEE Trans. Power Electron., vol. 26, no. 12, pp. 3491-3500, Dec. 2011.

[4] D.-Y. Kim, C.-E. Kim, and G.-W. Moon, "Variable Delay Time Method in Phase-Shifted Full-Bridge Converter for Reduced Power Consumption under Light Load Conditions," IEEE Trans. Power Electron., in press.

[5] W.-J. Lee, C.-E. Kim, G.-W. Moon, and S.-K. Han, "A New PhaseShifted Full-Bridge Converter With Voltage-Doubler-Type Rectifier for High-Efficiency PDP Sustaining Power Module," IEEE Trans. Ind. Electron., vol. 55, no. 6, Jun. 2008.

[6] Y.-S. Shin, C.-S. Kim, and S.-K. Han, "A Pulse-Frequency-Modulated Full-Bridge DC/DC Converter With Series Boost Capacitor," IEEE Trans. Ind. Electron., vol. 58, no. 11, Nov. 2011.

[7] I.-O. Lee, and G.-W. Moon, "Analysis and Design of Phase-Shifted Dual H-Bridge Converter with a Wide ZVS Range and Reduced Output Filter," IEEE Trans. Ind. Electron., in press.

[8] J. Dudrik, and N.-D. Trip, "Soft-Switching PS-PWM DC-DC Converter for Full-Load Range Applications," IEEE Trans. Ind. Electron., vol. 57, no. 8 , Aug. 2010

[9] C.-M. Wang, "A Novel ZCS-PWM Flyback Converter With a Simple ZCS-PWM Commutation Cell," IEEE Trans. Ind. Electron., vol. 55, no. 2, Feb. 2008.

[10] H.-S. Kim, J.-H. Jung, J.-W. Baek, and H.-J. Kim, "Analysis and Design of a Multi-output Converter using Asymmetrical PWM Half-bridge Flyback Converter Employing a Parallel-series Transformer," IEEE Trans. Ind. Electron., in press.

[11] Y. Jang, D. L. Dillman, and M. M. Jovanovic, "A New Soft-Switched PFC Boost Rectifier With Integrated Flyback Converter for Stand-by Power," IEEE Trans. Power Electron., vol. 21, no. 1, Jan. 2006.

[12] S.-Y. Cho, I.-O. Lee, J.-K. Kim, and G.-W. Moon, "A New Standby Structure Based on a Forward Converter Integrated With a Phase-Shift Full-Bridge Converter for Server Power Supplies," IEEE Trans. Power Electron., vol. 28, no. 1, Jan. 2013.

[13] J.-K. Kim, S.-W. Choi, C.-E. Kim, and G.-W. Moon, "A New Standby Structure Using Multi-Output Full-Bridge Converter Integrating Flyback Converter," IEEE Trans. Ind. Electron., vol. 58, no. 10, Oct. 2011. 